Article

\title{
Boron Nitride as a Novel Support for Highly Stable Palladium Nanocatalysts by Atomic Layer Deposition
}

\author{
Matthieu Weber ${ }^{1}$, Cassandre Lamboux ${ }^{1}$, Bruno Navarra ${ }^{1}$, Philippe Miele ${ }^{1,2}{ }^{\mathbb{D}}$, \\ Sandrine Zanna ${ }^{3}$, Maxime E. Dufond ${ }^{4}$, Lionel Santinacci ${ }^{4}$ and Mikhael Bechelany ${ }^{1, *(\mathbb{D}}$ \\ 1 Institut Européen des Membranes, IEM, UMR-5635, Univ Montpellier, CNRS, ENSCM, \\ 34095 Montpellier, France; matthieu.weber@umontpellier.fr (M.W.); cassandrelamboux@gmail.com (C.L.); \\ bruno.navarra@umontpellier.fr (B.N.); Philippe.Miele@umontpellier.fr (P.M.) \\ 2 Institut Universitaire de France, 1 rue Descartes, 75231 Paris, France \\ 3 PSL Research University, Chimie ParisTech-CNRS, Institut de Recherche de Chimie Paris, 75005 Paris, \\ France; sandrine.zanna@chimieparistech.psl.eu \\ 4 Aix Marseille Univ, CNRS, CINAM, 13009 Marseille, France; dufond@cinam.univ-mrs.fr (M.E.D.); \\ lionel.santinacci@univ-amu.fr (L.S.) \\ * Correspondence: mikhael.bechelany@umontpellier.fr; Tel.: +33-(0)4-6714-9167
}

Received: 24 September 2018; Accepted: 16 October 2018; Published: 18 October 2018

\begin{abstract}
The ability to prepare controllable nanocatalysts is of great interest for many chemical industries. Atomic layer deposition (ALD) is a vapor phase technique enabling the synthesis of conformal thin films and nanoparticles (NPs) on high surface area supports and has become an attractive new route to tailor supported metallic NPs. Virtually all the studies reported, focused on $\mathrm{Pd}$ NPs deposited on carbon and oxide surfaces. It is, however, important to focus on emerging catalyst supports such as boron nitride materials, which apart from possessing high thermal and chemical stability, also hold great promises for nanocatalysis applications. Herein, the synthesis of Pd NPs on boron nitride (BN) film substrates is demonstrated entirely by ALD for the first time. $\mathrm{X}$-ray photoelectron spectroscopy indicated that stoichiometric $\mathrm{BN}$ formed as the main phase, with a small amount of $\mathrm{BN}_{\mathrm{x}} \mathrm{O}_{\mathrm{y}}$, and that the Pd particles synthesized were metallic. Using extensive transmission electron microscopy analysis, we study the evolution of the highly dispersed NPs as a function of the number of ALD cycles, and the thermal stability of the ALD-prepared Pd/BN catalysts up to $750{ }^{\circ} \mathrm{C}$. The growth and coalescence mechanisms observed are discussed and compared with Pd NPs grown on other surfaces. The results show that the nanostructures of the BN/Pd NPs were relatively stable up to $500{ }^{\circ} \mathrm{C}$. Consequent merging has been observed when annealing the samples at $750{ }^{\circ} \mathrm{C}$, as the NPs' average diameter increased from $8.3 \pm 1.2 \mathrm{~nm}$ to $31 \pm 4 \mathrm{~nm}$. The results presented open up exciting new opportunities in the field of catalysis.
\end{abstract}

Keywords: palladium; nanocatalysts; boron nitride; atomic layer deposition

\section{Introduction}

Heterogeneous catalysis is at the heart of almost every established chemical process and is also crucial for the development of novel technologies in the fields of sustainable production and conversion of energy. Hence, different approaches have been developed to improve catalyst properties, aiming towards the promotion of catalytic reactions. Palladium nanoparticles (NPs) are known as very efficient catalysts, and the preparation of controllable and highly dispersed supported palladium NPs is therefore of huge interest for heterogeneous catalysis [1,2]. As the high surface-to-volume ratio of the particles is crucial in catalysis, palladium NPs with a narrow size distribution at the nanoscale are able to provide a high density of active sites available for catalysis. Therefore, enhancing atom 
efficiency and limiting the cost of this precious-metal catalyst [3-5]. In addition, since the catalytic activity of the metallic NPs depends on their size [6-9], the ability to synthesize stable and precisely engineered NPs in order to optimize their catalytic activity is highly desired. For example, in the case of alcohol oxidation, the intrinsic turnover frequency per surface $\mathrm{Pd}$ atom depends significantly on the nature of the substrates $[10,11]$ as well as on the diameter of Pd NPs and showed a maximum at a medium size of $4 \mathrm{~nm}[6]$.

An important factor affecting the metal catalysts is their relative lack of thermal stability, resulting in nanomaterials that have a lower specific surface area due to sintering. In industrial catalysis, the sintering of NPs and the degradation of the supports are often associated with the loss of the catalyst activity, which must be avoided if possible [12]. Therefore, the metallic "active" phase needs to be stable and prepared on a thermally strong support phase in order to be used in "real life" under high operating temperature conditions. It is known that catalytic activity highly depends on the size and geometry of the NPs but also on the particle interactions with its supports [13]. The structural changes and the loss of active surface area due to the particles' coalescence during operation lead to undesirable deactivation for supported catalysts, and new catalytic materials with enhanced stability must, therefore, be developed.

Typically, the support materials used for these metallic NPs are high melting point oxides and carbon-based materials $[2,14,15]$. However, as the design of catalytic nanomaterials with enhanced thermal stability is desired, it is important to focus on emerging catalyst supports such as boron nitride-based materials, which besides possessing extremely high thermal, mechanical, and chemical resistance [16-19], have also been recently investigated as hydrogen storage platforms and in nanocatalysis $[20,21]$. When compared to other support materials such as oxides and carbon, the potential of boron nitride (BN) as an innovative support for selective reactions has been demonstrated, especially for processes requiring high temperatures [22-26], and it has been shown that Pd NPs supported on BN open prospects for many catalytic reactions, such as the hydrogenation of lactose, for example [23,27-29].

Atomic layer deposition (ALD) is a vapor-phase deposition technique enabling the synthesis of ultrathin films of inorganic materials, such as oxides [30,31], nitrides [32-35], and metals [36,37], with a subnanometer thickness control [38,39]. ALD is based on the sequential use of self-limiting chemical reactions taking place in a cycle-wise manner, and a typical ALD cycle consists of alternate pulses of a precursor and co-reactant gases in the reactor, separated by purge or pumping steps. Obviously, each precursor or co-reactant in an ALD cycle has a profound impact on the process chemistry $[38,40]$. The benefits of the ALD method, especially the atomic-level thickness control, the excellent uniformity and conformality, enabled this route to emerge as an important technology for the deposition of thin films for a wide range of applications, from microelectronics [41] to biosensing [42] and from photovoltaics [43] to membranes [44]. For more information on this ALD technology, the reader is referred to excellent reviews already written [38,39,45-47].

The preparation of BN films by ALD is challenging, but several successful processes have been reported recently that enabled the deposition of $\mathrm{BN}$ with high uniformity and conformality $[32,34,48-54]$. Due to the difference of surface energies between the metal and the substrate surface [55], ALD of noble metals typically starts with the formation of isolated particles at the substrate surface, which grow and coalesce together with the increase of the number of cycles [56-58]. This peculiar nucleation-stage behavior can be used to prepare highly dispersed metallic NPs on high surface area supports and makes ALD a promising new route for the synthesis of nanocatalysts [56,57,59-63]. ALD of palladium NPs has been the subject of many studies, and the NPs have been deposited on different oxides, such as $\mathrm{Al}_{2} \mathrm{O}_{3}$ [37,64], $\mathrm{TiO} 2$ [65,66], $\mathrm{ZrO} 2$ [57], $\mathrm{SiO} 2$ [67], $\mathrm{SnO} 2$ [68], $\mathrm{NiO}$ [69] as well as on high aspect ratio carbon supports [70,71]. Furthermore, the catalytic activities of Pd NPs prepared by ALD have been assessed for different chemical reactions, such as ethanol [66]. Methanol [64], isopropanol [71], glucose [72] and glycerol oxidation [73]. 
The combination of Palladium NPs as active catalysts and BN as an innovative support material represent a very promising nanomaterial for heterogeneous catalysis. However, virtually all the $\mathrm{Pd}$ NPs synthesized by ALD have been prepared and studied on oxide and carbon supports. To the best of our knowledge, there is no work reporting on the preparation of palladium NPs by ALD on BN surfaces, despite its great potential. For the optimal use of these NPs, their structural changes and loss of active surface area due to particle coalescence need to be limited as much as possible. Recent studies have been dedicated to obtain a better understanding of the growth of metallic NPs by ALD, and to describe the pathways that lead from adsorbed single atoms to supported palladium NPs [56,74,75]. Although the growth of Pd NPs by ALD on oxides and their potential as active nanocatalysts for various chemical reactions have been reported, there is little understanding about Pd NPs on BN supports, nor about the stability of the NPs at high temperatures.

Herein, we synthesize this new class of Pd NPs/BN nanomaterials entirely by ALD, and we present a detailed study of the Pd NPs growth on BN surfaces. First, ALD of Pd and BN processes have been developed, and the preparation of BN films and Pd NPs is achieved. Using transmission electron spectroscopy (TEM) data, the evolution of the palladium NPs diameter as a function of the number of ALD cycles is presented, and the pathways leading from adsorbed single atoms to supported metallic NPs are discussed. Our data is compared to the data obtained from the literature in order to shed light on and to understand the growth of Pd NPs on BN surfaces. Furthermore, we study the chemical composition by X-ray photoelectron spectroscopy (XPS) as well as the thermal stability of the NPs, up to $750{ }^{\circ} \mathrm{C}$. The coalescence mechanisms observed are discussed and compared with Pd NPs grown by ALD on other surfaces.

\section{Materials and Methods}

\subsection{Atomic Layer Deposition of Boron Nitride}

All depositions have been carried out in a low-pressure hot-wall (home-built) ALD reactor. More details about this ALD reactor can be found in reference [34]. Boron tribromide $\left(\mathrm{BBr}_{3}\right)$ precursor was purchased from Sigma Aldrich (Saint-Louis, MO, USA) and used as received. The co-reactant was ammonia gas (Air Liquide, Paris, France). The precursor and co-reactant lines were directly connected to the reactor through gate valves and heated at $110{ }^{\circ} \mathrm{C}$ to avoid condensation. The deposition chamber was set at a temperature of $750{ }^{\circ} \mathrm{C}$. If not stated otherwise, the typical ALD cycle consisted of $0.1 \mathrm{~s}$ pulse of $\mathrm{BBr}_{3}, 5 \mathrm{~s}$ exposure, and $15 \mathrm{~s}$ purge, followed by a $3 \mathrm{~s}$ pulse of $\mathrm{NH}_{3}, 5 \mathrm{~s}$ exposure, and $15 \mathrm{~s}$ purge with Argon (Air Liquide, Paris, France). The silicon nitride TEM window grid substrates were $20 \mathrm{~nm}$ thick and purchased from Electron Microscopy Sciences (EMA, Hatfield, PA, USA). The p-type (100) silicon wafer substrates were purchased from MEMC Korea Company (Cheonan, South Korea). To remove the organic contaminants, the substrates were pre-cleaned in acetone, ethanol, and de-ionized water for $5 \mathrm{~min}$ in an ultrasonic bath before the depositions.

\subsection{Atomic Layer Deposition of Palladium}

All depositions have been done in a low-pressure hot-wall (home-built) ALD reactor, described elsewhere [73]. The precursor $\mathrm{Pd}(\mathrm{hfac})_{2}$ and co-reactant formalin were purchased from Sigma Aldrich (Saint-Louis, MO, USA). These precursor lines were heated at $70{ }^{\circ} \mathrm{C}$ and $100{ }^{\circ} \mathrm{C}$ for $\mathrm{Pd}(\mathrm{hfac})_{2}$ and formalin, respectively, to avoid condensation. The deposition chamber was set at a temperature of $220^{\circ} \mathrm{C}$. If not stated otherwise, the typical ALD cycle consisted of a $5 \mathrm{~s}$ pulse of $\mathrm{Pd}(\mathrm{hfac})_{2}, 15 \mathrm{~s}$ exposure, and $20 \mathrm{~s}$ purge, followed by a $1 \mathrm{~s}$ pulse of formalin, $15 \mathrm{~s}$ exposure, and $60 \mathrm{~s}$ purge with Argon.

\subsection{Thermal Treatments}

The thermal treatments have been carried out directly within the ALD reactor used for BN ALD, for $3 \mathrm{~h}$ under Ar gas, using a fast ramp rate of $45^{\circ} \mathrm{C} / \mathrm{min}$. 


\subsection{Transmission Electron Microscopy Imaging and Analysis of the Palladium NPS}

A JEOL 3010 high-resolution transmission electron microscope at $300 \mathrm{kV}$ (JEOL, Tokyo, Japan) has been used for the HR-TEM studies. The number of NPs, size distribution, and surface coverage were determined over areas of $400 \times 400 \mathrm{~nm}^{2}$ using the ImageJ software (NIH, MD, USA). The average diameter and its standard deviation were determined by averaging ten analyses of areas of $400 \times 400 \mathrm{~nm}^{2}$.

\subsection{Chemical Analysis}

XPS analysis was performed using a VG ESCALAB 250 spectrometer (ThermoFisher Scientific, Waltham, MA, USA) calibrated against the reference binding energies (BE) of clean $\mathrm{Cu}(932.6 \mathrm{eV})$, $\mathrm{Ag}(368.2 \mathrm{eV})$, and Au (84 eV) samples. Survey spectra and high-resolution spectra of the C 1s, B 1s, $\mathrm{N} 1 \mathrm{~s}, \mathrm{O}$ 1s, and $\mathrm{Pd} 3 \mathrm{~d}$ core-level regions were collected at a take-off angle of $90^{\circ}$ and a pass energy of 100 and $20 \mathrm{eV}$, respectively, using an $\mathrm{Al} \mathrm{K}$. monochromated X-ray source $(\mathrm{h} v=1486.6 \mathrm{eV})$. Data processing was performed using the CasaXPS analysis software using a Shirley-type background, component peaks defined by BE, Full Width at Half Maximum (FWHM) and Gaussian/Lorentzian envelopes. BEs of the component peaks were corrected with reference to the $\mathrm{C}$ 1s peak for $-\mathrm{CH}_{2}-\mathrm{CH}_{2}-$ bonds set at $285.0 \mathrm{eV}$.

\section{Results and Discussion}

First, an ALD process for the preparation of BN thin films has been employed to coat the TEM window grid substrates. The process consisted of sequential exposures of boron tribromide precursor $\left(\mathrm{BBr}_{3}\right)$ and $\mathrm{NH}_{3}$ gas, separated by purge steps of Argon at a temperature of $750{ }^{\circ} \mathrm{C}$. The BN films have been prepared (and measured by spectroscopic ellipsometry) on silicon with native oxide substrates in parallel to ensure the success of the ALD process. This process leads to the saturated growth of high quality BN thin films with a steady-state ALD growth of $\sim 0.8 \AA$ /cycle and no visible nucleation delay, as measured by spectroscopic ellipsometry $[34,58,76]$. Our process is based on the recipe developed by Marlid et al. [32] which studied the growth at different temperatures and showed that this ALD process based on $\mathrm{BBr}_{3}$ and $\mathrm{NH}_{3}$ enables the deposition of good quality $\mathrm{BN}$ films from 400 to (at least) $750{ }^{\circ} \mathrm{C}$, depicting the large temperature "ALD windows". As the microstructure observed at $750{ }^{\circ} \mathrm{C}$ was better than that which was observed at lower temperature, our process was applied at this temperature. The saturation curve of the $\mathrm{BN}$ film growth as a function of the $\mathrm{BBr}_{3}$ exposure time, depicting the saturated growth of the film, is given in the Supplementary Materials, Figure S1. Owing to the linearity of the process, the thickness of the prepared layers can be easily tuned. The detailed parameters of this process are given in the Experimental section, and more information can also be found elsewhere $[34,53,77]$. Several analytical methods have been used to characterize the $\mathrm{BN}$ films, and the growth-per-cycle, $\mathrm{C}$ and $\mathrm{O}$ contents, mass density, and roughness values are given in Table S1 (Supplementary Materials). In this study, in order to investigate the nanoparticles' growth on BN surfaces, we applied 200 cycles of this ALD process to coat $\mathrm{Si}_{3} \mathrm{~N}_{4}$ TEM window substrates with a BN film of approximately $15 \mathrm{~nm}$. Next, we used ALD of Palladium to deposit the Pd NPs on the BN surface. ALD of Palladium was based on $\mathrm{Pd}(\mathrm{hfac})_{2}$ and formalin precursors separated by Ar purged at $220^{\circ} \mathrm{C}$. The typical ALD cycle consisted of $5 \mathrm{~s}$ pulse of $\mathrm{Pd}(\mathrm{hfac})_{2}, 15 \mathrm{~s}$ exposure, and $20 \mathrm{~s}$ purge, followed by a $1 \mathrm{~s}$ pulse of formalin, $15 \mathrm{~s}$ exposure, and $60 \mathrm{~s}$ purge with Argon. The detailed process parameters are indicated in the Experimental section. Note that we already reported the use of this process for the preparation of Pd NPs by ALD on high aspect ratio carbon fibers, as well as their enhanced catalytic activity for glycerol oxidation [73].

In this work, in order to gain understanding on the formation and the growth of Pd NPs on BN surfaces, the BN coated TEM windows were used as substrates and 100, 200, and 300 cycles of Pd ALD cycles have been applied. TEM measurements have been performed in order to obtain information on 
the nanomaterials prepared. The data shown in Figure 1a-c presents the TEM images of the BN/Pd NPs as a function of the number of Pd ALD cycles.
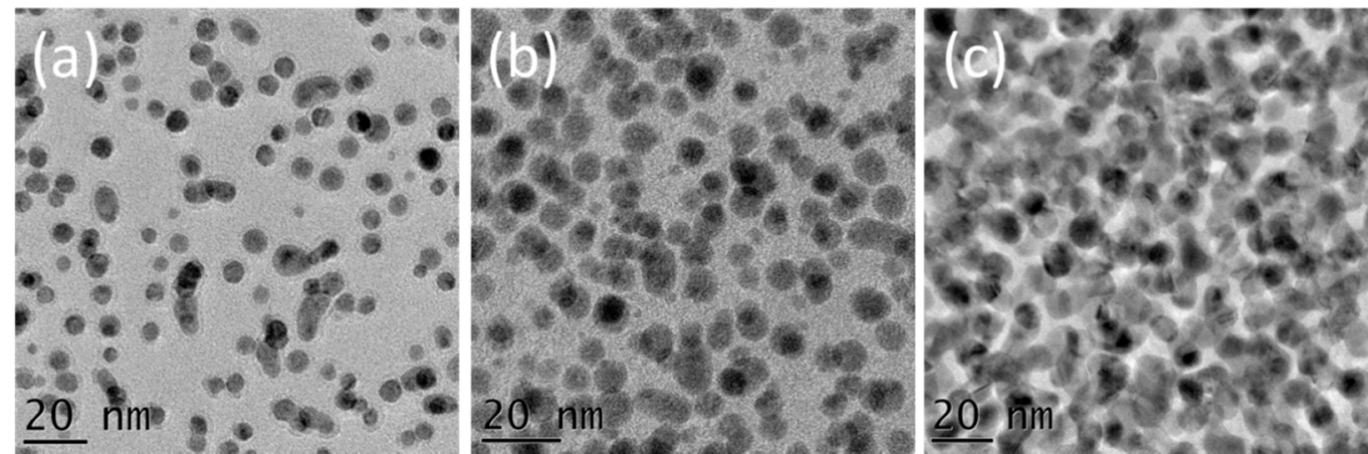

Figure 1. Transmission electron microscopy (TEM) images of boron nitride (BN) surfaces after (a) 100, (b) 200, and (c) 300 cycles of the Pd atomic layer deposition (ALD) process. The substrates used were $\mathrm{Si}_{3} \mathrm{~N}_{4}$ TEM windows covered with $15 \mathrm{~nm}$ of BN.

This figure illustrates that the particles' nucleation involves successive steps. Most of the Pd NPs are formed during the first 100 cycles. TEM data analysis, shown in Figure 2, revealed a surface density of $\sim 10^{13} \mathrm{NPs} / \mathrm{cm}^{2}$ and a surface coverage of $18 \% \pm 9 \%$. After 200 cycles, more NPs are formed all over the substrate and start to merge, reaching a surface coverage of $38 \% \pm 6 \%$. The surface density increased to $4 \times 10^{13} \mathrm{NPs} / \mathrm{cm}^{2}$. After 300 cycles, most of the NPs are merged, which can be described as particle coalescence. The surface coverage after 300 cycles is around $62 \% \pm 14 \%$. The difference in gray color between the NPs in the TEM images is related to the diffraction contrast, indicating that the deposited NPs are crystalline. In order to confirm this crystallinity, diffraction studies have been performed on a BN/Pd NPs sample prepared using 300 cycles of the Pd ALD process, sample shown in Figure 1c. Various crystal planes have been observed, as revealed by the selected area electron diffraction study carried out, see Figure S2 (Supplementary Materials).
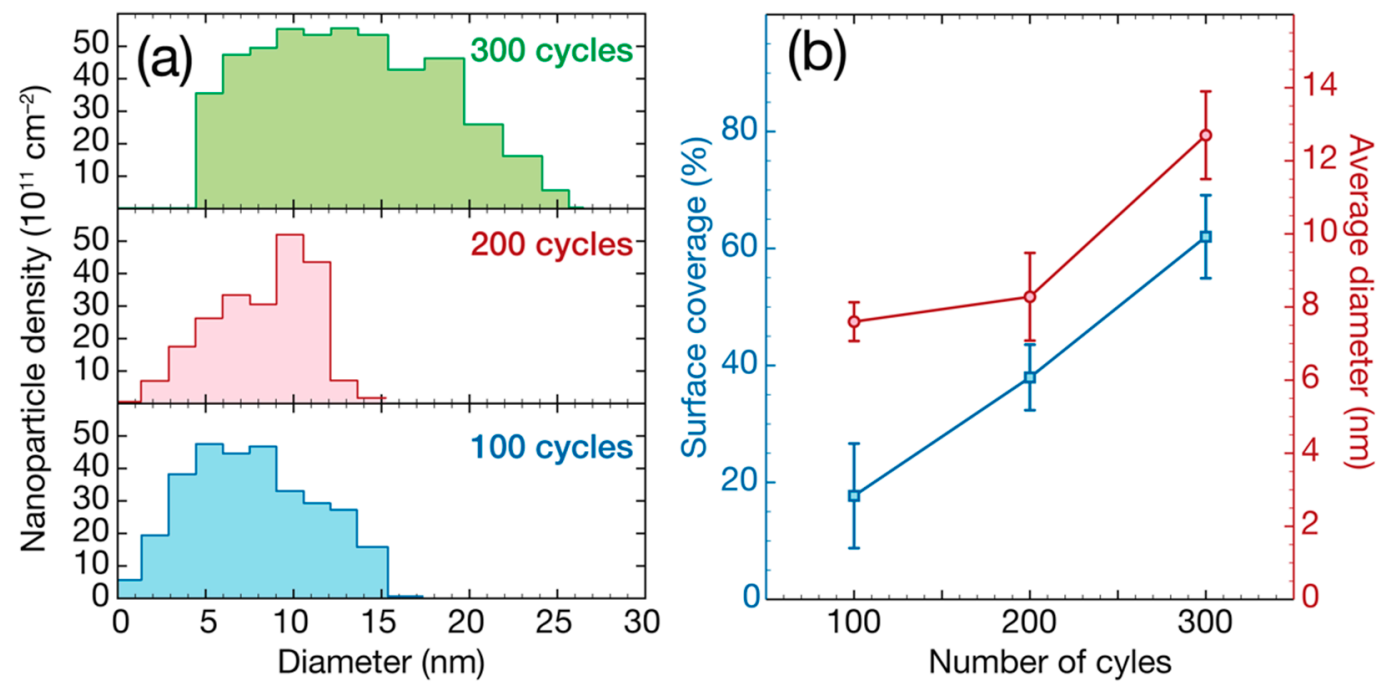

Figure 2. (a) Nanoparticle (NP) size distribution and (b) average diameter and surface density evolution of the Pd NPs on BN surfaces after 100, 200 and 300 ALD cycles (estimated). The data analysis is based on the TEM images presented in Figure 1.

Figure 2a presents the NP size distribution, and Figure $2 \mathrm{~b}$ shows the average diameter evolution for the Pd ALD process on BN surfaces after 100, 200, and 300 ALD cycles.

After 100 cycles, the NPs present an average diameter of $7.7 \pm 1.3 \mathrm{~nm}$. At 200 cycles, more Pd material is deposited and the average diameter value increased to $8.3 \pm 1.2 \mathrm{~nm}$. Finally, after 300 cycles, 
since the NPs are mostly merged, it is challenging to evaluate an average NP diameter, and we estimated it to be around $12.6 \pm 2.2 \mathrm{~nm}$. From this data, it can be deduced that the diameter of the Pd NPs increases with a growth rate of $\sim 0.02 \mathrm{~nm} /$ cycle between 100 and 300 cycles, which corresponds to a radial growth rate of $\sim 0.01 \mathrm{~nm} /$ cycle. This radial growth is two times lower than the rate observed for film growth using the same process ( $0.02 \mathrm{~nm} /$ cycle) [78]. However, the chemical reactions during ALD nucleation are different from the reactions taking place during film growth. The slow growth rate of the NPs observed could be explained by surface ligand pollution inhibiting the growth of the particles. This ligand pollution is known to be responsible for the long nucleation periods typically observed for ALD using precursors based on $\beta$-diketonates $[37,79,80]$. In fact, studies carried out previously have shown that $\mathrm{Pd}(\mathrm{hfac})_{2}$ adsorption (on alumina surfaces) results in both $\mathrm{Pd}(\mathrm{hfac})^{*}$ and $\mathrm{Al}(\mathrm{hfac})^{*}$ surface species. The $\mathrm{Al}(\mathrm{hfac})^{*}$ species appeared to act as site blockers for precursor adsorption. This surface poisoning by hfac ligands has been found to be partly responsible for the extended nucleation delay observed for Pd ALD on alumina [79,80]. However, similar poisoning is also expected for other surfaces such as nitrides, since the nucleation is also supposed to start at hydroxyl groups.

The surface composition of the BN/Pd nanomaterials deposited on $\mathrm{Si}$ wafers has been investigated by X-ray photoelectron spectroscopy. The XPS survey is presented in Figure 3a. After the ALD process, $\mathrm{B}, \mathrm{C}, \mathrm{N}, \mathrm{O}, \mathrm{Si}$, and $\mathrm{Pd}$ are detected. It indicates that the $\mathrm{B}, \mathrm{N}$, and $\mathrm{Pd}$ have effectively been deposited on the $\mathrm{Si}$ surface. The $\mathrm{C}$ and $\mathrm{O}$ could correspond to surface contamination and oxidation. As expected, no other elements are observed. The quantification indicates a $\mathrm{B} / \mathrm{N}$ ratio of 1.08 that is in line with the value of 1.13 when the $\mathrm{BN}$ is obtained from trichloroborazine [81]. Though it is not far from the unity it indicates that non-stoichiometric $\mathrm{BN}$ has been grown or that those elements are part of other compounds. Thus, the regions of interest have been investigated with a higher resolution in order to identify precisely the chemical nature of the film.

Figure $3 \mathrm{~b}-\mathrm{d}$ presents the $\mathrm{N}$ 1s (b), B 1s (c), and Pd 3d (d) peaks. The peak deconvolutions performed give valuable information on the chemical nature of the sample after the ALD of BN and $\mathrm{Pd}$. The $\mathrm{N} 1 \mathrm{~s}$ peak is deconvoluted using two contributions $N_{I}$ and $N_{I I}$. At low binding energy $(\mathrm{BE}=398.2 \mathrm{eV})$, the $N_{I}$ peak is expected because it corresponds to nitrogen in BN [82]. $N_{I I}$ located at higher $\mathrm{BE}(399.2 \mathrm{eV})$ can be attributed to the formation of $\mathrm{BN}_{\mathrm{x}} \mathrm{O}_{\mathrm{y}}$. It could indicate that a minor part of the $\mathrm{BN}$ reacts with oxygen to form a small amount of boron oxynitride. Similarly, the B 1s peak is fitted using two contributions: $B_{I}$ at $190.6 \mathrm{eV}$ and $B_{I I}$ at $191.4 \mathrm{eV}$. The $B_{I}$ contribution is ascribed to boron in $\mathrm{BN}$ [82] while $B_{I I}$ could correspond to $\mathrm{BN}_{\mathrm{x}} \mathrm{O}_{\mathrm{y}}$. This has been reported before [81] and is confirmed by the deconvolution of the $\mathrm{O} 1 \mathrm{~s}$ peak (not shown here) that is composed of four contributions: $530 \mathrm{eV}$ for $\mathrm{PdO} / \mathrm{PdO}_{2}, 531.8 \mathrm{eV}$ for the $\mathrm{Pd} 3 \mathrm{p}$ peak, $532.8 \mathrm{eV}$ for adsorbed oxygen and $\mathrm{H}_{2} \mathrm{O}$, and $535.15 \mathrm{eV}$ for $\mathrm{BN}_{\mathrm{x}} \mathrm{O}_{\mathrm{y}}$. As the Pd ALD process is expected to start with the reaction between the $\mathrm{Pd}(\mathrm{hfac})_{2}$ precursor molecules and hydroxyl groups, the additional $\mathrm{OH}$ groups created during the surface oxidation could actually aid the palladium nucleation. The deconvolution of the $\mathrm{Pd} 3 \mathrm{~d}$ peak. see Figure $3 \mathrm{~d}$, reveals that

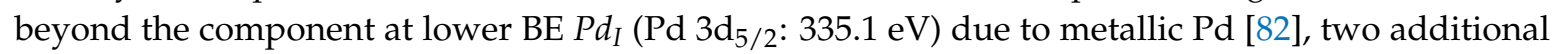
peaks $\left(P d_{I I}\right.$ and $\left.P d_{I I I}\right)$ are present at higher BEs (335.8 and $\left.337.3 \mathrm{eV}\right)$ [83]. These two peaks are attributed to palladium in the 2+ and 4+ oxidation states due to $\mathrm{PdO}$ and $\mathrm{PdO}_{2}$ and/or respective hydroxides. 

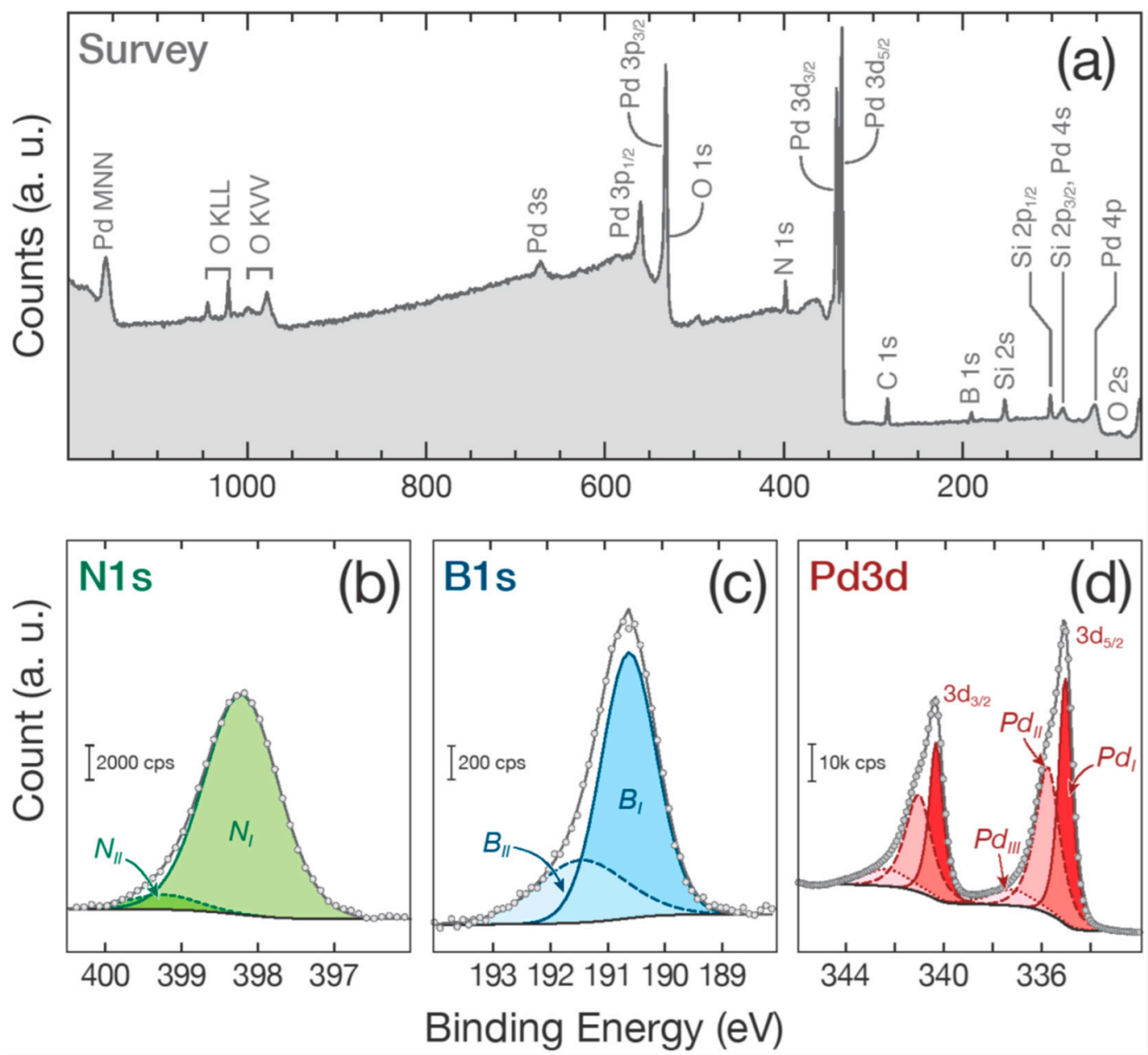

Figure 3. (a) XPS survey of the BN/Pd NPs sample. (b-d) present the N 1s, B 1s, and Pd $3 d$ deconvoluted peaks, respectively.

The data obtained can also be compared to results reported in the literature for other substrates. Assaud et al. used ALD of palladium on $\mathrm{TiO}_{2}$ surface for electrocatalytic applications and reported NPs of 6-8 $\mathrm{nm}$ after 400 cycles using a similar process based on $\mathrm{Pd}(\mathrm{hfac})_{2}$ and formalin [66]. Goldstein and George studied palladium ALD nucleation on an alumina surface and obtained NPs with an average diameter of $9.6 \pm 2.0 \mathrm{~nm}$ after 150 cycles using a similar process based on $\mathrm{Pd}(\mathrm{hfac})_{2}$, trimethyl alumina, and formalin [79]. Mackus et al. studied the nucleation of Pd ALD on $\mathrm{Al}_{2} \mathrm{O}_{3}$ surfaces and observed the long nucleation delay and slow growth rate of NPs as well. They found that the average diameter of the Pd NPs after 200 cycles was around $5 \mathrm{~nm}$ and increases with a rate of $\sim 0.014 \mathrm{~nm} /$ cycle [56]. Only Barr et al. have not found a long nucleation delay on $\mathrm{SnO}_{2}$, most likely because the formalin reduces the stannic oxide to metallic tin which exhibits a better interaction with Pd than the oxide [68]. Although the ALD processes used for these results on alumina were slightly different from ours, the values are comparable to the average diameter after 200 cycles $(8.4 \pm 1.4 \mathrm{~nm})$ and diameter growth of $\sim 0.02 \mathrm{~nm} /$ cycle that we obtained in our work where ALD of Pd was carried out on a boron nitride surface.

The fact that the diameter of the NPs slowly increases with the number of cycles brings a certain control on the tuning of the NPs by choosing the appropriate number of ALD cycles. The control of NPs dimensions is very important for heterogeneous catalysis applications. Many different parameters such as pressure, substrate temperature, and co-reactant exposure are involved in their growth but the formation of metallic NPs by ALD is mainly based on the difference in the surface energies between the metal and the substrate surface, diffusion processes, and the ALD precursors' chemistries $[56,74,75,84]$. 
As discussed in the introduction, highly dispersed NPs presenting a narrow size distribution are desired in order to obtain the largest density of active sites potentially available for catalysis. Using our Pd ALD process on a BN surface, the samples obtained using 200 cycles of Pd ALD appear to be optimized, presenting a high surface density of $4 \times 10^{13} \mathrm{NPs} / \mathrm{cm}^{2}$. This surface density value is comparable to the typical values obtained for Pd or Pt NPs on oxide surfaces $\left(10^{12}-10^{13} \mathrm{NPs} / \mathrm{cm}^{2}\right)[55,56,74,75]$. The structural changes and the loss of active surface area due to the particle coalescence during industrial operation lead to undesirable deactivation for supported catalysts. Therefore, thermally stable catalytic materials are desired. Therefore, the stability of the synthesized BN/Pd NPs catalysts under high-temperature conditions has been studied. For this purpose, the BN/Pd NPs obtained using 200 cycles were submitted to different heat treatments. In order to carry out the thermal stability study, the samples prepared with 200 cycles were heated to 500 and $750{ }^{\circ} \mathrm{C}$ for $3 \mathrm{~h}$ (under constant Ar gas flow). Figure 4 presents TEM images of the Pd NPs/BN catalysts after heating treatments at 500 and $750{ }^{\circ} \mathrm{C}$ for $3 \mathrm{~h}$.

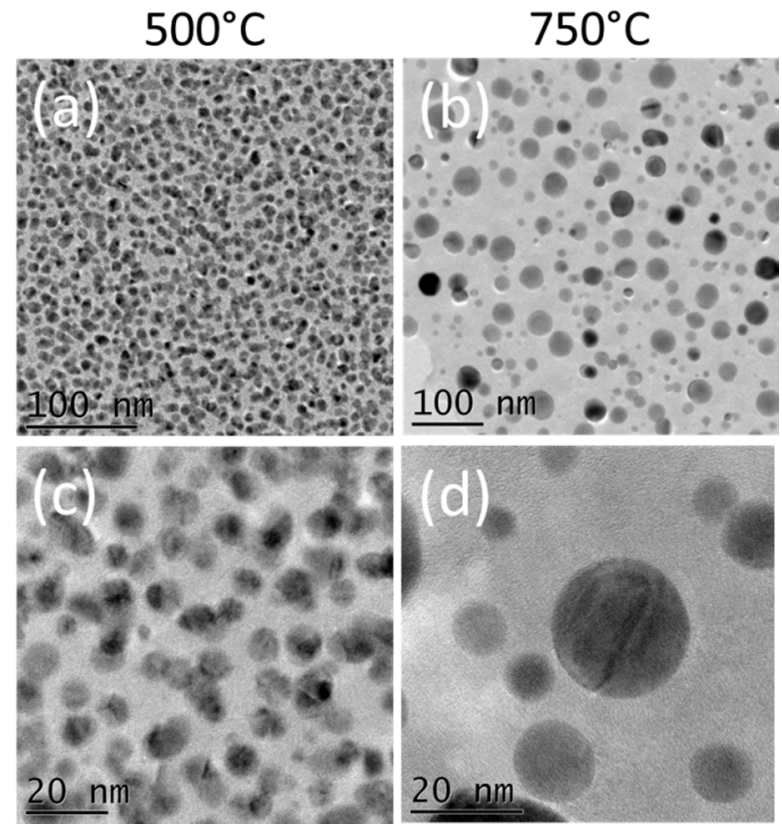

Figure 4. TEM images of Pd NPs on BN surfaces prepared by applying 200 cycles of the Pd ALD process, after heating treatments at $(\mathbf{a}, \mathbf{c}) 500{ }^{\circ} \mathrm{C}$ and $(\mathbf{b}, \mathbf{d}) 750{ }^{\circ} \mathrm{C}$ for $3 \mathrm{~h}$. The substrates used were $\mathrm{Si}_{3} \mathrm{~N}_{4}$ TEM window grids covered with $15 \mathrm{~nm}$ of $\mathrm{BN}$.

For NPs on any surfaces, there are two limiting cases of the kinetics of dimensional changes: (i) Coalescence, in which NPs adhere poorly to the surface, permitting them to diffuse across it and to coalesce; (ii) Ostwald ripening, in which the NPs adhere strongly to the surface, making atomic transfer between NPs more favorable. The Ostwald ripening process is the main form of thermal annealing for metallic NPs that are well separated and supported on a surface, although coalescence can occur for a high density of clusters [55,85]. From Figure $4 \mathrm{a}, \mathrm{c}$, it can be seen that the NPs annealed at $500{ }^{\circ} \mathrm{C}$ present a very similar morphology to the as-deposited ones at $220^{\circ} \mathrm{C}$, see Figure $1 \mathrm{~b}$. A slight increase in the average diameter is however observed. TEM data analysis showed that this diameter increased from $8 \mathrm{~nm}$ to $11 \mathrm{~nm}$. As expected, this merging of NPs resulted in a decrease in surface coverage, which was reduced from $38 \% \pm 6 \%$ to $28 \% \pm 3 \%$ after heat treatment at $500{ }^{\circ} \mathrm{C}$ when compared to the Pd NPs prepared at $220^{\circ} \mathrm{C}$. From the small shift in size distribution, a profile skewed more toward larger particles can be seen, suggesting that Oswald ripening took place as the main mechanism for the formation of larger NPs. However, these changes are expected to be relatively unharmful for potential catalysis applications, since the NPs diameter remains small and narrow, and the surface density remains high (value of $4 \times 10^{13} \mathrm{NPs} / \mathrm{cm}^{2}$ ). 
After annealing at $750^{\circ} \mathrm{C}$, the morphology of the NPs changes considerably. First, consequent merging between the NPs can be seen, and it can be observed as well that the NPs' surface becomes slightly smoother, see Figure $4 \mathrm{~b}, \mathrm{~d}$. As revealed from the TEM data analysis presented in Figure 5, the average diameter increases to $31 \pm 4 \mathrm{~nm}$, whereas the surface coverage is reduced to $20 \% \pm 7 \%$. Furthermore, the density of NPs decreases by an order of magnitude to $10^{12} \mathrm{NPs} / \mathrm{cm}^{2}$. The enthalpy of activation of the coalescence between Pd NPs is directly dependent on the temperature [85], and $750{ }^{\circ} \mathrm{C}$ is in this case sufficient for this mechanism to take place at a "large" scale. Once the NPs adhere poorly to the surface and are able to diffuse across it, this coalescence mechanism is in fact favorable, as its driving force is the surface energy reduction (because the surface area of the new NP is less than that of the sum of the surface areas of the original smaller NPs). Due to the high mobility of Pd atoms on the high-temperature BN surface, surface-mediated Ostwald ripening sintering, in which material is transferred from one NP to another by diffusion across the substrate surface, is also very likely to take place, as a competitive process. The fact that the surface of the NPs seems spherical and smooth also indicates an easy diffusion of Pd atoms at the surface of the NPs, forming, thermodynamically speaking, a more stable NP shape.
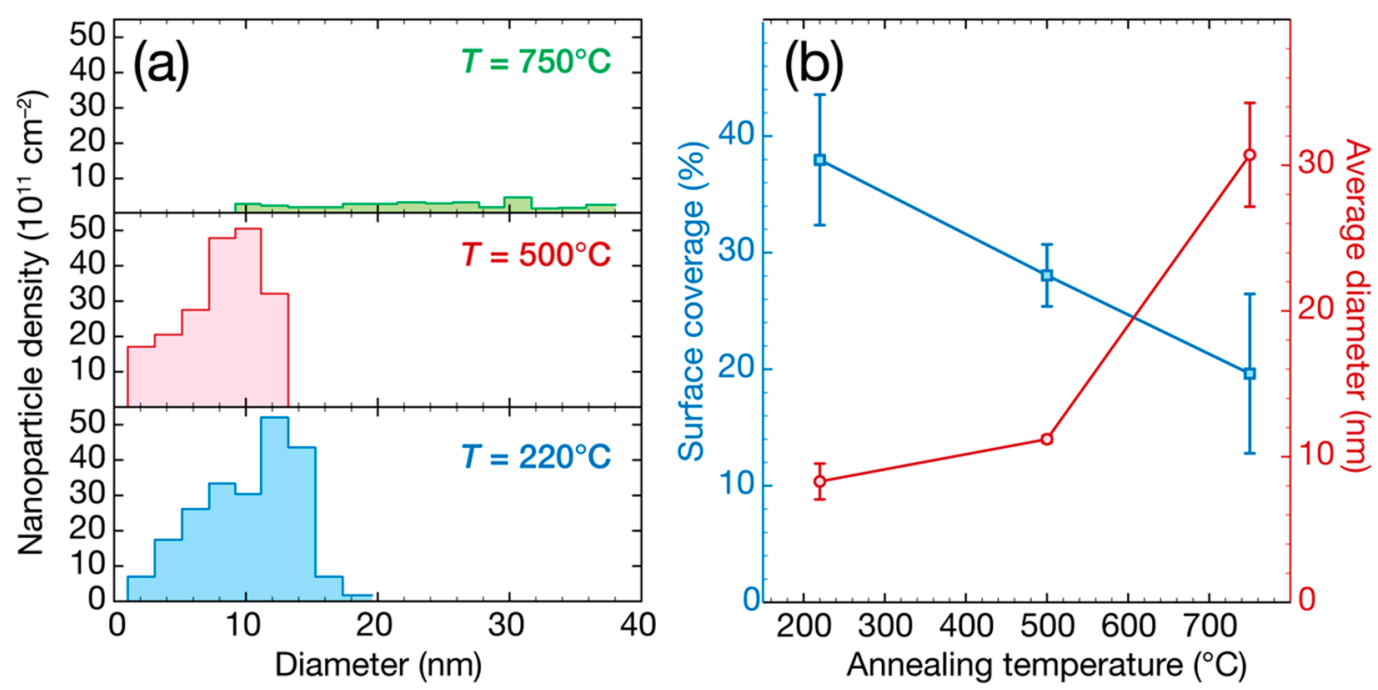

Figure 5. (a) Nanoparticle size distribution and (b) average diameter and surface coverage evolution of the Pd NPs on BN surfaces, as prepared at $220^{\circ} \mathrm{C}$ and after thermal treatments at 500 and $750{ }^{\circ} \mathrm{C}$ for $3 \mathrm{~h}$. The data analysis is based on the TEM images presented in Figure 4.

From these results, it can be concluded that up to $500^{\circ} \mathrm{C}$, the morphology of the Pd NPs supported on $\mathrm{BN}$ remain relatively stable, opening opportunities for their use as catalysts at this temperature. However, consequent merging between the NPs has been observed for the annealed sample at $750{ }^{\circ} \mathrm{C}$, due to the diffusion of atoms and NPs at this high temperature. These data allow for insights into the underlying mechanism of supported palladium NPs on BN supports to be gained, paving the way toward the rational design of this novel type of supported catalysts with controlled activity and stability.

\section{Conclusions}

In this work, we reported the synthesis of $\mathrm{BN} / \mathrm{Pd}$ nanomaterials entirely by ALD. The thickness of the BN support and the size of the Pd NPs are easily controllable by varying the number of ALD cycles applied. After 200 cycles, the NPs were highly dispersed $\left(10^{13} \mathrm{NPs} / \mathrm{cm}^{2}\right)$ and presented an average diameter of $8.3 \pm 1.2 \mathrm{~nm}$. X-ray photoelectron spectroscopy analysis indicated that the Pd NPs were metallic and prepared on stoichiometric BN. The thermal stability study carried out revealed that the ALD-prepared Pd NPs supported on BN surface were relatively stable up to $500{ }^{\circ} \mathrm{C}$ and covered approximately $28 \%$ of the surface, but their morphology drastically changed when heated at higher 
temperatures. At $750{ }^{\circ} \mathrm{C}$, the NPs were involved in a merging process, and their average diameter consequently increased up to $31 \mathrm{~nm}$, whereas the surface coverage and dispersion were reduced to $20 \%$ and $10^{12} \mathrm{NPs} / \mathrm{cm}^{2}$, respectively. This study brings more understanding on the growth and thermal stability of this new type of BN/Pd NPs, which is valuable for their potential use as nanocatalysts at high temperature and opens up novel opportunities in the field of heterogeneous catalysis.

Supplementary Materials: The following are available online at http:/ /www.mdpi.com/2079-4991/8/10/849/s1. Table S1: Properties of BN films prepared by ALD using $\mathrm{BBr}_{3}$ as precursor and $\mathrm{NH}_{3}$ as co-reactant at $750{ }^{\circ} \mathrm{C}$. Figure S1: Saturation curve of the BN film growth as a function of the BBr3 exposure time, depicting the saturated growth of the film. Figure S2: Selected area electron diffraction of a BN/Pd NPs sample prepared using 300 cycles of the Pd ALD process, corresponding to Figure 1c. The substrates used were $\mathrm{Si}_{3} \mathrm{~N}_{4}$ TEM windows covered with $15 \mathrm{~nm}$ of $\mathrm{BN}$. The table corresponds to the indexing of the diffraction rings.

Author Contributions: Conceptualization and methodology, M.W.; ALD experiments, C.L. and M.W.; data analysis, S.Z., M.D. and L.S.; writing and editing, M.W. and L.S.; project administration, P.M. and M.B.; funding acquisition, P.M. and M.B.

Funding: This research was funded by the French national research agency (ANR, program MeNiNA-ANR17-CE09-0049). The support of the COST Action MP1402 "HERALD", a European cooperation program, is acknowledged.

Conflicts of Interest: The authors declare no conflict of interest.

\section{References}

1. Gallon, B.J.; Kojima, R.W.; Kaner, R.B.; Diaconescu, P.L. Palladium nanoparticles supported on Polyaniline nanofibers as a semi-heterogeneous catalyst in Water. Angew. Chem. Int. Ed. 2007, 46, 7251-7254. [CrossRef] [PubMed]

2. Thomas, J.M.; Thomas, W.J. Principles and Practice of Heterogeneous Catalysis; John Wiley \& Sons: Hoboken, NJ, USA, 2014.

3. Kim, B.H.; Hackett, M.J.; Park, J.; Hyeon, T. Synthesis, characterization, and application of ultrasmall nanoparticles. Chem. Mater. 2013, 26, 59-71. [CrossRef]

4. Campelo, J.M.; Luna, D.; Luque, R.; Marinas, J.M.; Romero, A.A. Sustainable preparation of supported metal nanoparticles and their applications in catalysis. Chem. Sus. Chem. 2009, 2, 18-45. [CrossRef] [PubMed]

5. White, R.J.; Luque, R.; Budarin, V.L.; Clark, J.H.; Macquarrie, D.J. Supported metal nanoparticles on porous materials. Methods and applications. Chem. Soc. Rev. 2009, 38, 481-494. [CrossRef] [PubMed]

6. Chen, J.; Zhang, Q.; Wang, Y.; Wan, H. Size-dependent catalytic activity of supported palladium nanoparticles for aerobic oxidation of alcohols. Adv. Synth. Catal. 2008, 350, 453-464. [CrossRef]

7. Xu, Z.; Xiao, F.-S.; Purnell, S.K.; Alexeev, O.; Kawi, S.; Deutsch, S.E.; Gates, B.C. Size-dependent catalytic activity of supported metal clusters. Nature 1994, 372, 346-348. [CrossRef]

8. Shao, M.; Peles, A.; Shoemaker, K. Electrocatalysis on platinum nanoparticles: Particle size effect on oxygen reduction reaction activity. Nano Lett. 2011, 11, 3714-3719. [CrossRef] [PubMed]

9. Rioux, R.M.; Song, H.; Grass, M.; Habas, S.; Niesz, K.; Hoefelmeyer, J.D.; Yang, P.; Somorjai, G.A. Monodisperse platinum nanoparticles of well-defined shape: Synthesis, characterization, catalytic properties and future prospects. Top. Catal. 2006, 39, 167-174. [CrossRef]

10. Tauster, S.J.; Fung, S.C.; Garten, R.L. Strong metal-support interactions. Group 8 noble metals supported on titanium dioxide. J. Am. Chem. Soc. 1978, 100, 170-175. [CrossRef]

11. Monyoncho, E.A.; Ntais, S.; Brazeau, N.; Wu, J.; Sun, C.; Baranova, E.A. Role of the metal-oxide support in the catalytic activity of $\mathrm{Pd}$ nanoparticles for ethanol electrooxidation in alkaline media. Chem Electro.Chem. 2016, 3, 218-227. [CrossRef]

12. Argyle, M.D.; Bartholomew, C.H. Heterogeneous catalyst deactivation and regeneration: A review. Catalysts 2015, 5, 145-269. [CrossRef]

13. Sun, X.A.; Saha, M.S. Nanotubes, nanofibers and nanowires as supports for catalysts. In PEM Fuel Cell Electrocatalysts and Catalyst Layers; Zhang, J., Ed.; Springer: London, UK, 2008; pp. 655-714.

14. Prasad, R.; Kennedy, L.A.; Ruckenstein, E. Catalytic combustion. Catal. Rev. Sci. Eng. 1984, 26, 1-58. [CrossRef] 
15. Bauer, J.E.; Occelli, M.L.; Williams, P.M.; McCaslin, P.C. Heterogeneous catalyst structure and function: Review and implications for the analysis of dissolved organic carbon and nitrogen in natural waters. Mar. Chem. 1993, 41, 75-89. [CrossRef]

16. Bechelany, M.; Brioude, A.; Stadelmann, P.; Bernard, S.; Cornu, D.; Miele, P. Preparation of BN microtubes/nanotubes with a unique chemical process. J. Phys. Chem. C 2008, 112, 18325-18330. [CrossRef]

17. Lipp, A.; Schwetz, K.A.; Hunold, K. Hexagonal boron nitride: Fabrication, properties and applications. J. Eur. Ceram. Soc. 1989, 5, 3-9. [CrossRef]

18. Chen, Y.; Zou, J.; Campbell, S.J.; Le Caer, G. Boron nitride nanotubes: Pronounced resistance to oxidation. Appl. Phys. Lett. 2004, 84, 2430-2432. [CrossRef]

19. Bernard, S.; Salles, V.; Li, J.; Brioude, A.; Bechelany, M.; Demirci, U.B.; Miele, P. High-yield synthesis of hollow boron nitride nano-polyhedrons. J. Mater. Chem. 2011, 21, 8694-8699. [CrossRef]

20. Weng, Q.; Wang, X.; Zhi, C.; Bando, Y.; Golberg, D. Boron nitride porous microbelts for hydrogen storage. ACS Nano 2013, 7, 1558-1565. [CrossRef] [PubMed]

21. Li, J.; Lin, J.; Xu, X.; Zhang, X.; Xue, Y.; Mi, J.; Mo, Z.; Fan, Y.; Hu, L.; Yang, X. Porous boron nitride with a high surface area: Hydrogen storage and water treatment. Nanotechnology 2013, 24, 155603. [CrossRef] [PubMed]

22. Postole, G.; Caldararu, M.; Ionescu, N.I.; Bonnetot, B.; Auroux, A.; Guimon, C. Boron nitride: A high potential support for combustion catalysts. Thermochim. Acta 2005, 434, 150-157. [CrossRef]

23. Meyer, N.; Bekaert, K.; Pirson, D.; Devillers, M.; Hermans, S. Boron nitride as an alternative support of Pd catalysts for the selective oxidation of lactose. Catal. Commun. 2012, 29, 170-174. [CrossRef]

24. Wu, J.C.S.; Chen, C.-Y.; Lin, S.D. Boron nitride supported Pt catalyst for selective hydrogenation. Catal. Lett. 2005, 102, 223-227. [CrossRef]

25. Gao, L.; Fu, Q.; Wei, M.; Zhu, Y.; Liu, Q.; Crumlin, E.; Liu, Z.; Bao, X. Enhanced nickel-catalyzed methanation confined under hexagonal boron nitride shells. ACS Catal. 2016, 6, 6814-6822. [CrossRef]

26. Schimmenti, R.; Cortese, R.; Duca, D.; Mavrikakis, M. Boron Nitride-supported Sub-nanometer Pd6 Clusters for Formic Acid Decomposition: A DFT Study. ChemCatChem. 2017, 9, 1610-1620. [CrossRef]

27. Meyer, N.; Devillers, M.; Hermans, S. Boron nitride supported Pd catalysts for the hydrogenation of lactose. Catal. Today 2015, 241, 200-207. [CrossRef]

28. Yabe, Y.; Sawama, Y.; Yamada, T.; Nagata, S.; Monguchi, Y.; Sajiki, H. Easily-controlled chemoselective hydrogenation by using palladium on boron nitride. ChemCatChem. 2013, 5, 2360-2366. [CrossRef]

29. Zuo, L.-X.; Jiang, L.-P. Electrocatalysis of the oxygen reduction reaction and the formic acid oxidation reaction on BN/Pd composites prepared sonochemically. J. Electrochem. Soc. 2017, 164, H805-H811. [CrossRef]

30. Ritala, M.; Kukli, K.; Rahtu, A.; Räisänen, P.I.; Leskelä, M.; Sajavaara, T.; Keinonen, J. Atomic layer deposition of oxide thin films with metal alkoxides as oxygen sources. Science 2000, 288, 319-321. [CrossRef] [PubMed]

31. Hämäläinen, J.; Ritala, M.; Leskelä, M. Atomic layer deposition of noble metals and their oxides. Chem. Mater. 2013, 26, 786-801. [CrossRef]

32. Mårlid, B.; Ottosson, M.; Pettersson, U.; Larsson, K.; Carlsson, J.O. Atomic layer deposition of BN thin films. Thin Solid Films 2002, 402, 167-171. [CrossRef]

33. Kim, H. Atomic layer deposition of metal and nitride thin films: Current research efforts and applications for semiconductor device processing. J. Vac. Sci. Technol. B Microelectron. Nano. Struct. Process. Meas. Phenom. 2003, 21, 2231-2261. [CrossRef]

34. Weber, M.; Koonkaew, B.; Balme, S.; Utke, I.; Picaud, F.; Iatsunskyi, I.; Coy, E.; Miele, P.; Bechelany, M. Boron nitride nanoporous nembranes with high surface charge by atomic layer deposition. ACS Appl. Mater. Interfaces 2017, 9, 16669-16678. [CrossRef] [PubMed]

35. Assaud, L.; Pitzschel, K.; Hanbücken, M.; Santinacci, L. Highly-conformal TiN thin films grown by thermal and plasma-enhanced atomic layer deposition. ECS J. Solid State Sci. Technol. 2014, 3, 253-258. [CrossRef]

36. Aaltonen, T.; Ritala, M.; Tung, Y.-L.; Chi, Y.; Arstila, K.; Meinander, K.; Leskelä, M. Atomic layer deposition of noble metals: Exploration of the low limit of the deposition temperature. J. Mater. Res. 2004, 19, 3353-3358. [CrossRef]

37. Weber, M.J.; Mackus, A.J.M.; Verheijen, M.A.; Longo, V.; Bol, A.A.; Kessels, W.M.M. Atomic layer deposition of high-purity palladium films from $\mathrm{Pd}(\mathrm{hfac})_{2}$ and $\mathrm{H}_{2}$ and $\mathrm{O}_{2}$ plasmas. J. Phys. Chem. C 2014, 118, 8702. [CrossRef] 
38. Leskelä, M.; Ritala, M. Atomic layer deposition (ALD): From precursors to thin film structures. Thin Solid Films 2002, 409, 138-146. [CrossRef]

39. George, S.M. Atomic layer deposition: An overview. Chem. Rev. 2010, 110, 111-131. [CrossRef] [PubMed]

40. Putkonen, M. Precursors for ALD Processes. In Atomic Layer Deposition of Nanostructured Materials; John Wiley \& Sons: Hoboken, NJ, USA, 2012; pp. 41-59.

41. Zaera, F. The surface chemistry of thin film atomic layer deposition (ALD) processes for electronic device manufacturing. J. Mater. Chem. 2008, 18, 3521-3526. [CrossRef]

42. Graniel, O.M.; Weber, S.; Balme, P.; Miele, M.B. Atomic layer deposition for biosensing applications. Biosens. Bioelectron. 2018, 122, 147-159. [CrossRef] [PubMed]

43. Van Delft, J.A.; Garcia-Alonso, D.; Kessels, W.M.M. Atomic layer deposition for photovoltaics: Applications and prospects for solar cell manufacturing. Semicond. Sci. Technol. 2012, 27, 74002. [CrossRef]

44. Weber, M.A.; Julbe, A.; Ayral, P.; Miele, M.B. Atomic layer deposition for membranes: Basics, challenges and opportunities. Chem. Mater. 2018. [CrossRef]

45. Marichy, C.; Bechelany, M.; Pinna, N. Atomic layer deposition of nanostructured materials for energy and environmental applications. Adv. Mater. 2012, 24, 1017-1032. [CrossRef] [PubMed]

46. Detavernier, C.; Dendooven, J.; Pulinthanathu Sree, S.; Ludwig, K.F.; Martens, J.A. Tailoring nanoporous materials by atomic layer deposition. Chem. Soc. Rev. 2011, 40, 5242-5253. [CrossRef] [PubMed]

47. Van Bui, H.; Grillo, F.; van Ommen, J.R. Atomic and molecular layer deposition: Off the beaten track. Chem. Commun. 2017, 53, 45-71. [CrossRef] [PubMed]

48. Ferguson, J.D.; Weimer, A.W.; George, S.M. Atomic layer deposition of boron nitride using sequential exposures of $\mathrm{BCl} 3$ and $\mathrm{NH} 3$. Thin Solid Films 2002, 413, 16-25. [CrossRef]

49. Olander, J.; Ottosson, L.M.; Heszler, P.; Carlsson, J.-O.; Larsson, K.M.E. Laser-assisted atomic layer deposition of boron nitride thin films. Chem. Vap. Depos. 2005, 11, 330-337. [CrossRef]

50. Park, H.; Kim, T.K.; Cho, S.W.; Jang, H.S.; Lee, S.I.; Choi, S.-Y. Large-scale synthesis of uniform hexagonal boron nitride films by plasma-enhanced atomic layer deposition. Sci. Rep. 2017, 7, 40091. [CrossRef] [PubMed]

51. Hemmi, A.; Bernard, C.; Cun, H.; Roth, S.; Klöckner, M.; Weinl, M.; Gsell, S.; Schreck, M.; Osterwalder, J.; Greber, T. High quality single atomic layer deposition of hexagonal boron nitride on single crystalline $\mathrm{Rh}(111)$ four-inch wafers. Rev. Sci. Instrum. 2014, 85, 35101. [CrossRef] [PubMed]

52. Sprenger, J.K.; Sun, H.; Cavanagh, A.S.; Roshko, A.; Blanchard, P.T.; George, S.M. Electron-enhanced atomic layer deposition of boron nitride thin films at room temperature and $100{ }^{\circ} \mathrm{C}$. J. Phys. Chem. C 2018, 122, 9455-9464. [CrossRef]

53. Weber, M.; Iatsunskyi, I.; Coy, E.; Miele, P.; Cornu, D.; Bechelany, M. Novel and facile route for the synthesis of tunable boron nitride nanotubes combining atomic layer deposition and annealing processes for water purification. Adv. Mater. Interfaces 2018, 5, 18-56. [CrossRef]

54. Hao, W.; Marichy, C.; Journet, C.; Brioude, A. A novel two-step ammonia-free atomic layer deposition approach for boron nitride. Chem. Nano. Mat. 2017, 3, 656-663. [CrossRef]

55. Campbell, C.T. Ultrathin metal films and particles on oxide surfaces: Structural, electronic and chemisorptive properties. Surf. Sci. Rep. 1997, 27, 1-111. [CrossRef]

56. Mackus, A.J.M.; Weber, M.J.; Thissen, N.F.W.; Garcia-Alonso, D.; Vervuurt, R.H.J.; Assali, S.; Bol, A.A.; Verheijen, M.A.; Kessels, W.M.M. Atomic layer deposition of Pd and Pt nanoparticles for catalysis: On the mechanisms of nanoparticle formation. Nanotechnology 2016, 27, 34001. [CrossRef] [PubMed]

57. Elam, J.W.; Zinovev, A.V.V.; Pellin, M.J.; Comstock, D.J.; Hersam, M.C. Nucleation and growth of noble metals on oxide surfaces using atomic layer deposition. ECS Trans. 2007, 3, 271-278. [CrossRef]

58. Leick, N.; Weber, J.W.; Mackus, A.J.M.; Weber, M.J.; Van de Sanden, M.C.M.; Kessels, W.M.M. In situ spectroscopic ellipsometry during atomic layer deposition of Pt, Ru and Pd. J. Phys. D Appl. Phys. 2016, 49, 115504. [CrossRef]

59. O’Neill, B.J.; Jackson, D.H.K.; Lee, J.; Canlas, C.; Stair, P.C.; Marshall, C.L.; Elam, J.W.; Kuech, T.F.; Dumesic, J.A.; Huber, G.W. Catalyst design with atomic layer deposition. ACS Catal. 2015, 5, 1804-1825. [CrossRef]

60. Lu, J.; Elam, J.W.; Stair, P.C. Synthesis and stabilization of supported metal catalysts by atomic layer deposition. Acc. Chem. Res. 2013, 46, 1806-1815. [CrossRef] [PubMed] 
61. Christensen, S.T.; Feng, H.; Libera, J.L.; Guo, N.; Miller, J.T.; Stair, P.C.; Elam, J.W. Supported Ru- Pt bimetallic nanoparticle catalysts prepared by atomic layer deposition. Nano Lett. 2010, 10, 3047-3051. [CrossRef] [PubMed]

62. Weber, M.J.; Verheijen, M.A.; Bol, A.A.; Kessels, W.M.M. Sub-nanometer dimensions control of core/shell nanoparticles prepared by atomic layer deposition. Nanotechnology 2015, 26, 94002. [CrossRef] [PubMed]

63. Weber, M.J.; Mackus, A.J.M.; Verheijen, M.A.; van der Marel, C.; Kessels, W.M.M. Supported Core/Shell Bimetallic Nanoparticles Synthesis by Atomic Layer Deposition. Chem. Mater. 2012, 24, 2973-2977. [CrossRef]

64. Feng, H.; Elam, J.W.; Libera, J.A.; Setthapun, W.; Stair, P.C. Palladium catalysts synthesized by atomic layer deposition for methanol decomposition. Chem. Mater. 2010, 22, 3133-3142. [CrossRef]

65. Lu, J.; Stair, P.C. Low-temperature ABC-type atomic layer deposition: Synthesis of highly uniform ultrafine supported metal nanoparticles. Angew. Chem. Int. Ed. 2010, 49, 2547-2551. [CrossRef] [PubMed]

66. Assaud, L.; Brazeau, N.; Barr, M.K.S.; Hanbucken, M.; Ntais, S.; Baranova, E.A.; Santinacci, L. Atomic layer deposition of $\mathrm{Pd}$ nanoparticles on $\mathrm{TiO}_{2}$ nanotubes for ethanol electrooxidation: Synthesis and electrochemical properties. ACS Appl. Mater. Interfaces 2015, 7, 24533-24542. [CrossRef] [PubMed]

67. Ten Eyck, G.A.; Pimanpang, S.; Bakhru, H.; Lu, T.; Wang, G. Atomic layer deposition of Pd on an oxidized metal substrate. Chem. Vap. Depos. 2006, 12, 290-294. [CrossRef]

68. Barr, M.K.S.; Assaud, L.; Brazeau, N.; Hanbucken, M.; Ntais, S.; Santinacci, L.; Baranova, E.A. Enhancement of $\mathrm{Pd}$ catalytic activity toward ethanol electrooxidation by atomic layer deposition of $\mathrm{SnO}_{2}$ onto $\mathrm{TiO}_{2}$ Nanotubes. J. Phys. Chem. C 2017, 121, 17727-17736. [CrossRef]

69. Assaud, L.; Monyoncho, E.; Pitzschel, K.; Allagui, A.; Petit, M.; Hanbücken, M.; Baranova, E.A.; Santinacci, L. 3D-nanoarchitectured $\mathrm{Pd} / \mathrm{Ni}$ catalysts prepared by atomic layer deposition for the electrooxidation of formic acid. Beilstein J. Nanotechnol. 2014, 5, 162. [CrossRef] [PubMed]

70. Gong, T.; Qin, L.; Zhang, W.; Wan, H.; Lu, J.; Feng, H. Activated carbon supported palladium nanoparticle catalysts synthesized by atomic layer deposition: Genesis and evolution of nanoparticles and tuning the particle size. J. Phys. Chem. C 2015, 119, 11544-11556. [CrossRef]

71. Rikkinen, E.; Santasalo-Aarnio, A.; Airaksinen, S.; Borghei, M.; Viitanen, V.; Sainio, J.; Kauppinen, E.I.; Kallio, T.; Krause, A.O.I. Atomic layer deposition preparation of Pd nanoparticles on a porous carbon support for alcohol oxidation. J. Phys. Chem. C 2011, 115, 23067-23073. [CrossRef]

72. Liang, X.; Lyon, L.B.; Jiang, Y.-B.; Weimer, A.W. Scalable synthesis of palladium nanoparticle catalysts by atomic layer deposition. J. Nanoparticles Res. 2012, 14, 943. [CrossRef]

73. Weber, M.; Collot, P.; El Gaddari, H.; Tingry, S.; Bechelany, M.; Holade, Y. Enhanced catalytic glycerol oxidation activity enabled by activated-carbon-supported palladium catalysts prepared through atomic layer deposition. Chem. Electro. Chem. 2018, 5, 743-747. [CrossRef]

74. Grillo, F.; Moulijn, J.A.; Kreutzer, M.T.; van Ommen, J.R. Nanoparticle sintering in atomic layer deposition of supported catalysts: Kinetic modeling of the size distribution. Catal. Today 2018, 316, 51-61. [CrossRef]

75. Grillo, F.; Van Bui, H.; Moulijn, J.A.; Kreutzer, M.T.; van Ommen, J.R. Understanding and controlling the aggregative growth of platinum nanoparticles in atomic layer deposition: An avenue to size selection. J. Phys. Chem. Lett. 2017, 8, 975-983. [CrossRef] [PubMed]

76. Langereis, E.; Heil, S.B.S.; Knoops, H.C.M.; Keuning, W.; Van de Sanden, M.C.M.; Kessels, W.M.M. In situ spectroscopic ellipsometry as a versatile tool for studying atomic layer deposition. J. Phys. D Appl. Phys. 2009, 42, 73001. [CrossRef]

77. Weber, M.; Coy, E.; Iatsunskyi, I.; Yate, L.; Miele, P.; Bechelany, M. Mechanical properties of boron nitride thin films prepared by atomic layer deposition. CrystEngComm 2017, 19, 6089-6094. [CrossRef]

78. Elam, J.W.; Zinovev, A.; Han, C.Y.; Wang, H.H.; Welp, U.; Hryn, J.N.; Pellin, M.J. Atomic layer deposition of palladium films on $\mathrm{Al}_{2} \mathrm{O}_{3}$ surfaces. Thin Solid Films 2006, 515, 1664-1673. [CrossRef]

79. Goldstein, D.N.; George, S.M. Enhancing the nucleation of palladium atomic layer deposition on $\mathrm{Al}_{2} \mathrm{O}_{3}$ using trimethylaluminum to prevent surface poisoning by reaction products. Appl. Phys. Lett. 2009, 95, 143106. [CrossRef]

80. Goldstein, D.N.; George, S.M. Surface poisoning in the nucleation and growth of palladium atomic layer deposition with Pd (hfac) 2 and formalin. Thin Solid Films 2011, 519, 5339-5347. [CrossRef]

81. Postole, G.; Bonnetot, B.; Gervasini, A.; Guimon, C.; Auroux, A.; Ionescu, N.I.; Caldararu, M. Characterisation of BN-supported palladium oxide catalyst used for hydrocarbon oxidation. Appl. Catal. A Gen. 2007, 316, 250-258. [CrossRef] 
82. Moulder, J.F.; Stickle, W.F.; Sobol, P.E.; Bomben, K.D. Handbook of X-ray photoelectron spectroscopy: A reference book of standard spectra for identification and interpretation of XPS data; Perkin-Elmer Corporation: Waltham, MA, USA, 1995.

83. Shafeev, G.A.; Themlin, J.; Bellard, L.; Marine, W.; Cros, A. Enhanced adherence of area-selective electroless metal plating on insulators. J. Vac. Sci. Technol. 1996, 14, 319-326. [CrossRef]

84. Grillo, F.; Van Bui, H.; La Zara, D.; Aarnink, A.A.I.; Kovalgin, A.Y.; Kooyman, P.; Kreutzer, M.T.; van Ommen, J.R. From Single Atoms to Nanoparticles: Autocatalysis and Metal Aggregation in Atomic Layer Deposition of Pt on $\mathrm{TiO}_{2}$ Nanopowder. Small 2018, 14, 1800765. [CrossRef] [PubMed]

85. Jose-Yacaman, M.; Gutierrez-Wing, C.; Miki, M.; Yang, D.-Q.; Piyakis, K.N.; Sacher, E. Surface diffusion and coalescence of mobile metal nanoparticles. J. Phys. Chem. B 2005, 109, 9703-9711. [CrossRef] [PubMed]

2018 by the authors. Licensee MDPI, Basel, Switzerland. This article is an open access article distributed under the terms and conditions of the Creative Commons Attribution (CC BY) license (http:/ / creativecommons.org/licenses/by/4.0/). 